\title{
Chapter 4 \\ Applying Stakeholder Perspectives \\ to Sustainable Biofuel Strategy: A Summary \\ of Our Analyses
}

\author{
Masahiro Matsuura and Hideaki Shiroyama
}

\subsection{Producers in Developing Nations}

Toward the mass production of biofuels for transportation and other uses, feedstock production is increasingly dependent on developing nations in South America and Southeast Asia. For instance, multiple sections in Part II focused on the production of sugarcane-based bioethanol in Brazil. Chapter 2.2.1 will analyze the impact of increased production of sugarcane in Brazil on forest, land, and water uses. In a similar vein, Chap. 2.1.2 will discuss various methods of bioethanol production that would eventually contribute to the ultimate goal of deploying biofuels, which is to reduce the GHG emission. Chapter 2.2.2 will also discuss various methods of production with focus on regional impacts. Chapter 2.3.1 will provide an overview of stakeholders in Brazilian bioethanol and Indonesian biodiesel production sectors. These chapters focus on producers' influence on the environment, as well as the influence on varieties of stakeholders in the production of biofuels.

In the context of regulating biofuels, "producers" of feedstock are often characterized as profit-seeking plantation owners that contribute to the degradation of natural environment and living environment of indigenous people. The reality in the field of production in developing nations, however, is far more complex. Different kinds of plantation owners exist, varying by the scale of capital and the main market. Plantation owners are not the sole decision-maker in the feedstock production. Many independent small-scale farmers still exist.

\footnotetext{
M. Matsuura $(\bowtie)$

Graduate School of Governance Studies, Meiji University, 1-1 Kanda Surugadai, Chiyoda-ku, Tokyo 101-8301, Japan e-mail: mmatsuura@meiji.ac.jp

H. Shiroyama

Graduate School of Law and Politics, The University of Tokyo, Tokyo, Japan 
In addition, distilling and refining feedstock into biofuel is a major question in terms of profit, particularly in the case of Indonesian biodiesel. The refinery part of the biofuel production is far more profitable than feedstock production, while the former requires capital investments and technology. Therefore, some part of Indonesian crude palm oil is transferred to Singapore for final processes, which makes Indonesian stakeholders demand "fair" share. In the case of bioethanol in Brazil, biofuel production plants are often integrated with conventional sugar cane production plants. Therefore, research and development for better refinery system occurs in Brazil, which allows the country to fully benefit from increased production of bioethanol. Advanced technologies and their benefit to Brazilian communities will be further discussed in Chap. 2.1.2 (Table 4.1).

\subsection{Users in Developing Nations}

While discourses on biofuels are often focused on the increasing demand for biofuels at the global scale because of the need to offset GHG emissions, domestic users are in fact the major players in the deployment of biofuels. Brazil's Pró-Álcool policy in response to the oil crisis of 1973 was successful in achieving the marketscale production of bioethanols, supported by the introduction of flex-fuel technologies in the early 2000s. Indonesia is also promoting the domestic use of biodiesels by providing subsidies particularly because of its increasing demand for conventional fossil fuels and the subsequent need to import oil and gas. In the light of transportation and marketing costs as well as environmental footprint, it would be far smarter to use them domestically, rather than to export them to developed nations. Therefore, the "energy independence" discourse, instead of "green innovation" discourse, supports the domestic production and uses of biofuels within the developing nations (i.e., the same logic applies to the US policy for domestic production and use of bioethanol).

On the other hand, the frustrating experience with Jatropha curcas in many South Asian nations suggests the need of reframing its position in the varieties of biofuel options. Jatropha was once promoted as a method of increasing the biofuel production in arid areas where palm and other plantations are relatively difficult. The promotion of Jatropha, however, has been unsuccessful in many parts particularly because of the unstable demand for biofuel feedstock as well as the frustrating yields compared to what had been promised in pitched promotion. In response, Chap. 2.2.2 articulates a more realistic strategy for Jatropha curcas. Households in the rural parts of Southeast Asian nations are still suffering from the shortage of basic needs, including fuels. Instead of letting them cut down trees without much concerns on sustainability, Jatropha curcas could be useful in sustaining the life of rural villages by providing sustainable fuels for household. 


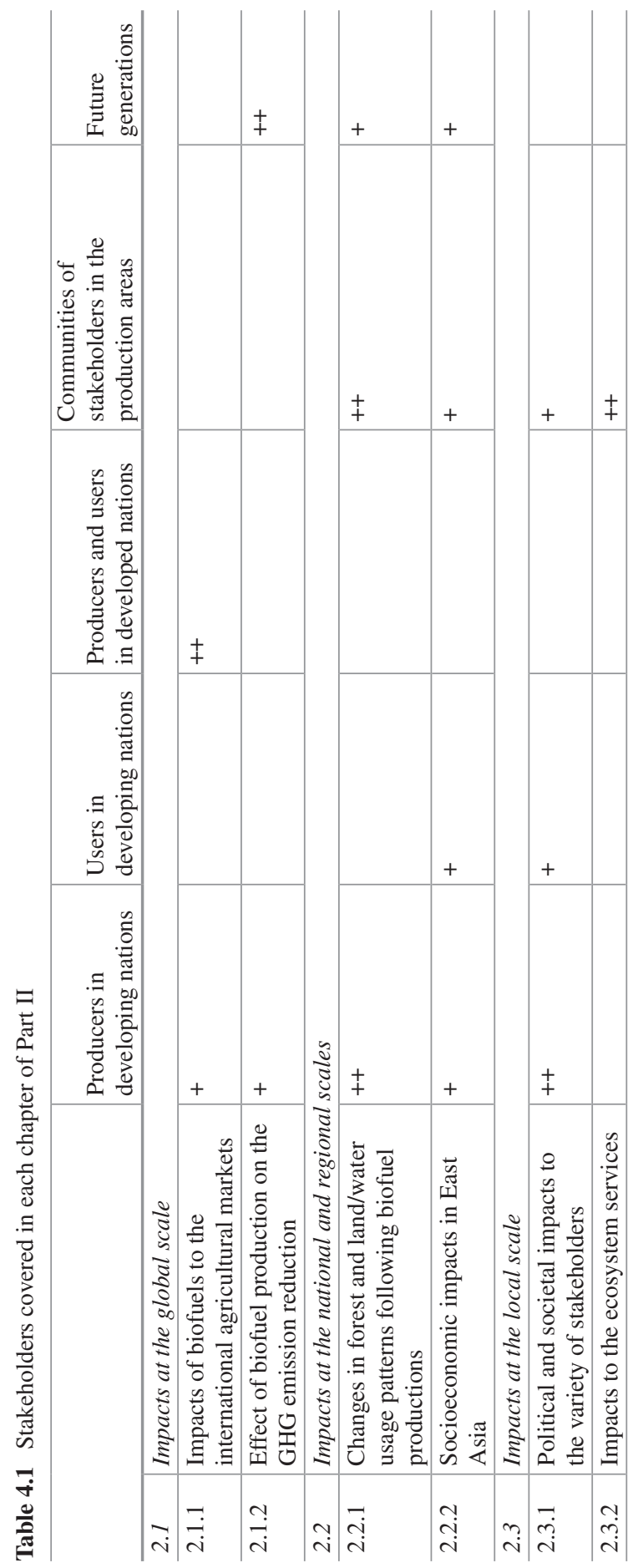




\subsection{Producers and Users in Developed Nations}

Chapter 2.1.1 is a unique, but foremost important, chapter in Part II, because it will primarily deal with producers and users of biofuel in the United States. While Brazil would be the first successful nation to propagate the use of biofuel through its PróÁlcool policy, the renewed interest in biofuels in the twenty-first century was initially triggered by the US federal government's substantial investments in the further use of biofuels produced by domestic corns and soybeans. Its influence is formidable because using these feedstocks for biofuels directly competes with other conventional uses, which are vegetable oil and food as such. The added demand for these crops can trigger price hikes infiltrated by opportunistic investments in future option markets. In addition, wide varieties of government subsidies to producers, often motivated by political interests, in the name of "green innovation" distort the value of these crops. Nonetheless, the bioethanol production in the United States has been steadily increasing even until $2011^{1}$, and the troubling nature of biofuels that entertain competition between fuel use and food use can become a major issue in 2012 when the North American farmers are hit by a major drought.

Users in the developing nations are also major stakeholders because they can influence the demand for biofuels worldwide. Chapter 2.3.1 will touch on this issue. In particular, the EU member states and many states of the United States have mandates regarding the mix of biofuels in the conventionally marketed automobile fuels. For instance, EU's Directive 2009/28/EC mandates each member state to turn the $10 \%$ of its transportation fuels into biofuels before 2020. This kind of mandate influences the global demand for biofuels. Users in developed nations are also concerned about rainforests and fair trade. Therefore, the governments of these nations have been exploring the use of accreditation schemes for biofuels so that their policy for increasing the use of biofuels would not harm the interests of these domestic NGOs and other interest groups.

\subsection{Communities of Stakeholders in the Production Areas}

There are many "other" key stakeholders in the field of production. For instance, Chap. 2.2.1 articulates the impact of increased production of feedstocks on the environment. In Brazil, there is strong concern, particularly among international environmental NGO communities, about the expansion of plantations into rainforest and in Cerrado. Even if a marginal expansion of plantation takes a piece of relatively less environmentally valuable land, it can have a spillover effect on water resources and other competing land uses such as cattle herding. These indirect impacts must be addressed in considering the expansion of biofuel uses and Chap. 2.2.1 tries to address these issues by analyzing such impacts quantitatively. Chapter

\footnotetext{
${ }^{1}$ http://www.ethanolrfa.org/pages/statistics
} 
2.3.2 provides an overview of similar impacts from the perspective of ecosystem services.

Natural environment and resources are not only the key stakeholders related to production. For instance, Chap. 2.3.1 provides an overview of the relevant stakeholders in Brazil and Indonesia. Investors and trade firms play an integral role in developing the supply chain of biofuels. In Brazil, the national development bank, BNDES, plays a pivotal role in developing advanced facilities that can flexibly produce both crude sugar and bioethanol. Trade farms are also important in facilitating infrastructure developments for exporting biofuels at a large scale. Without an appropriate involvement of these stakeholders, the expansion of biofuel uses, particularly at the global scale, is unlikely. Labor organizations are also important. Plantations hire a number of manual seasonal laborers for harvesting. Once the biofuels are exported to developed nations, international communities will be more concerned about the working environment and "fair" share of profit between the plantation owners and laborers.

\subsection{Future Generations}

The last, but requiring a serious attention, category of biofuel deployment stakeholders is our future generations. The foremost goal of deploying biofuels at the global scale is to reduce the carbon emission, which will eventually curtail the risk of damage from a major climate change. Chapter 2.1.2 addresses this question by comparing various methods of biofuel production that can most reduce the GHG emission. While feedstock captures $\mathrm{CO} 2$ when it grows, the procedures of turning it into fuels in fact emit CO2. Chapter 2.1.2 therefore introduces the life cycle analysis perspective to measure the effect of various kinds of production method. In its analysis, the effect of using bagasse - the residue of sugar cane-for electricity production is substantial because the increasing demand for electricity in Brazil would lead to an increased dependence on coal-fired power plants.

\subsection{Summary}

This chapter reviewed how the stakeholder perspectives are applied to our analyses of biofuel deployment with different methods. While the discourse on biofuels has often focused on the impact of expanded production on the surrounding natural environment, the impact is far more extended to a wide variety of stakeholders. In reality, the issues around biofuel are not just a polarized debate between proexpansion and anti-expansion. A number of actors, such as investors, manual laborers, and end-use consumers in developed nations, play a pivotal role in the chain of actions from production to consumption. In addition, political discourses often 
negate the foremost important stakeholders: the future generation. They are the ones who would eventually benefit from the curtailed carbon emissions. As is reviewed in this chapter, there is a clear need to draw a holistic picture of biofuel stakeholders in the field. In the next chapter, varieties of discourse over the biofuel uses are reviewed using the analytical framework called "ontology."

Open Access This chapter is licensed under the terms of the Creative Commons AttributionNonCommercial 2.5 International License (http://creativecommons.org/licenses/by-nc/2.5/), which permits any noncommercial use, sharing, adaptation, distribution and reproduction in any medium or format, as long as you give appropriate credit to the original author(s) and the source, provide a link to the Creative Commons license and indicate if changes were made.

The images or other third party material in this chapter are included in the chapter's Creative Commons license, unless indicated otherwise in a credit line to the material. If material is not included in the chapter's Creative Commons license and your intended use is not permitted by statutory regulation or exceeds the permitted use, you will need to obtain permission directly from the copyright holder.

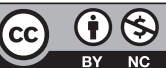

